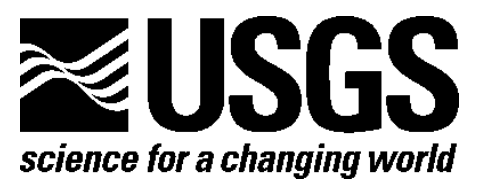

\title{
Mars Global Digital Dune Database (MGD³)-Composition, Stability, and Thermal Inertia
}

By Amber L. Gullikson, Rosalyn K. Hayward, Timothy N. Titus, Heather Charles, Lori K. Fenton, Rachael H. Hoover, and Nathaniel E. Putzig

Open-File Report 2018-1164

U.S. Department of the Interior U.S. Geological Survey 


\section{U.S. Department of the Interior \\ RYAN K. ZINKE, Secretary}

\section{U.S. Geological Survey James F. Reilly II, Director}

U.S. Geological Survey, Reston, Virginia: 2018

For more information on the USGS—-the Federal source for science about the Earth, its natural and living resources, natural hazards, and the environment-visit https://www.usgs.gov/ or call 1-888-ASK-USGS (1-888-275-8747).

For an overview of USGS information products, including maps, imagery, and publications, visit https://store.usgs.gov/.

Any use of trade, firm, or product names is for descriptive purposes only and does not imply endorsement by the U.S. Government.

Although this information product, for the most part, is in the public domain, it also may contain copyrighted materials as noted in the text. Permission to reproduce copyrighted items must be secured from the copyright owner.

\section{Suggested citation:}

Gullikson, A.L., Hayward, R.K., Titus, T.N., Charles, H., Fenton, L.K., Hoover, R., and Putzig, N.E., 2018, Mars global digital dune database $\left(\mathrm{MGD}^{3}\right)$-Composition, stability, and thermal inertia: U.S. Geological Survey Open-File Report 2018-1164, 17 p., https://doi.org/10.3133/ofr20181164. 


\section{Acknowledgments}

This work was supported by NASA through the Planetary Geology and Geophysics program via grants NNH14AX981 and NNX17AB25G. We are grateful to Christopher Edwards and Glen Cushing for their insightful comments which have greatly improved this report. 


\section{Contents}

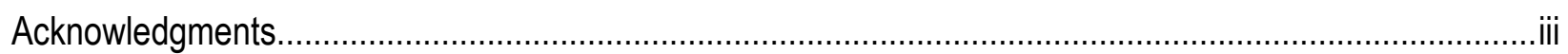

Abstract ………

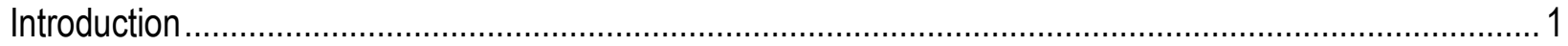

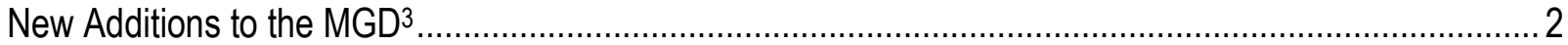

Thermal and Compositional Dune-Field Analysis ....................................................................... 2

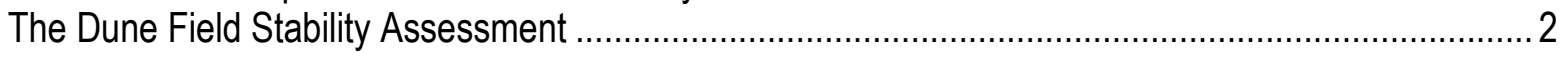

THEMIS ATI and two-component heterogeneity modeling ……................................................... 3

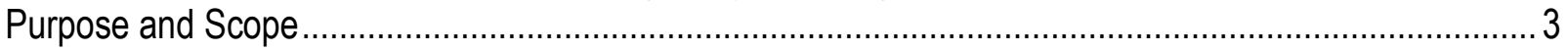

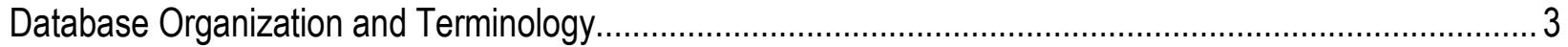

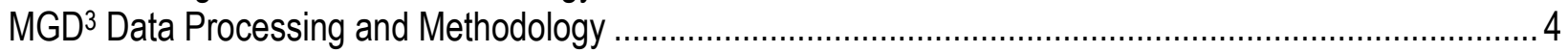

TES Observational Data........................................................................................................... 4

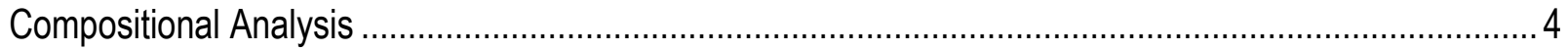

Stability Index

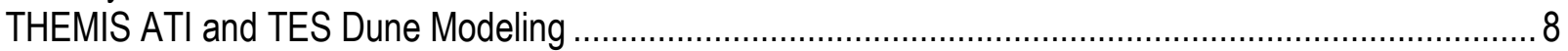

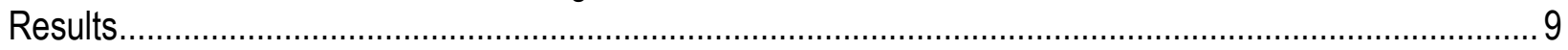

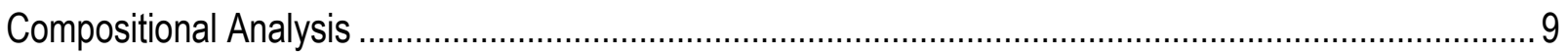

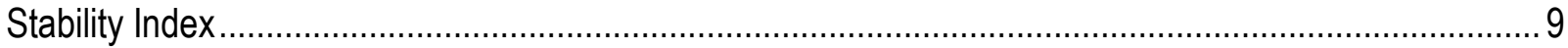

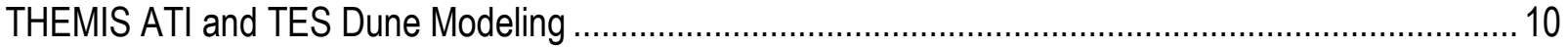

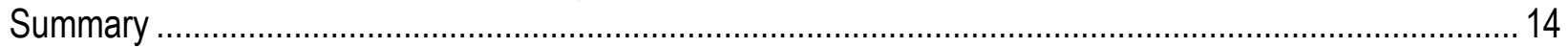

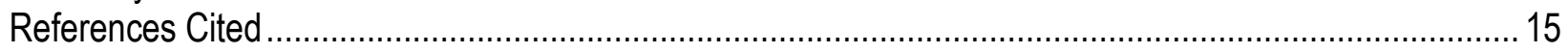

Appendix...................................................... Available online only at https://doi.org/10.3133/ofr20181164

\section{Figures}

1. THEMIS VIS images of dune fields exhibiting the six stability index morphological categories ........6

2. HiRISE images showing examples of non-aeolian features forming on dunes ............................... 7

3. MOLA global shaded relief map of Mars topography showing dune fields included in the compositional analysis.

4. Global albedo maps of Mars showing locations of dune fields and their corresponding mineral abundances

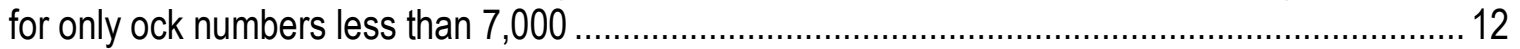

5. Plots showing latitude of dune fields used in the compositional analysis (for all ock numbers, including those greater than 7,000 ) versus averaged albedo and averaged nighttime thermal inertia derived values from the TES thermal infrared bolometer.

6. MOLA global shaded relief map of Mars topography showing dune-field locations included in the stability

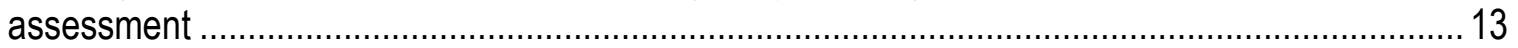

7. Plot showing the latitudinal distribution of smaller-scale stability features visible in HiRISE images14

\section{Tables}

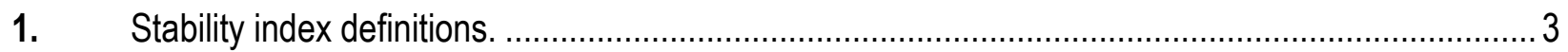

2. Data selection parameters for Thermal Emission Spectrometer (TES) data................................... 6

\section{Supplementary Material}

Equatorial Dune Database

South Polar Dune Database ...
Available online only at https://doi.org/10.3133/ofr20181164 Available online only at https://doi.org/10.3133/ofr20181164 


\section{Conversion Factors}

International System of Units to U.S. customary units

\begin{tabular}{lcll}
\hline & Multiply & By & To obtain \\
\hline & Length & & \\
\hline centimeter $(\mathrm{cm})$ & 0.3937 & inch (in.) & \\
millimeter $(\mathrm{mm})$ & 0.03937 & inch (in.) & \\
micrometer $(\mu \mathrm{m})$ & 0.00003937 & inch (in.) & \\
meter $(\mathrm{m})$ & 3.281 & foot (ft) & \\
kilometer $(\mathrm{km})$ & 0.6214 & mile (mi) & \\
meter $(\mathrm{m})$ & 1.094 & yard (yd) & \\
\hline & Area & \\
\hline square kilometer $\left(\mathrm{km}^{2}\right)$ & 247.1 & acre \\
square kilometer $\left(\mathrm{km}^{2}\right)$ & 0.3861 & square mile $\left(\mathrm{mi}^{2}\right)$ \\
\hline
\end{tabular}

Temperature in kelvin $(\mathrm{K})$ may be converted to degrees Celsius $\left({ }^{\circ} \mathrm{C}\right)$ as ${ }^{\circ} \mathrm{C}=\mathrm{K}-273.15$

Temperature in kelvin $(\mathrm{K})$ may be converted to degrees Fahrenheit $\left({ }^{\circ} \mathrm{F}\right)$ as ${ }^{\circ} \mathrm{F}=(1.8 \times(\mathrm{K}-273.15))+32$.

\section{Datum}

The coordinate system used through this report is the IAU Mars 2000. 


\section{Abbreviations}

$\begin{array}{ll}\text { ATI } & \text { apparent thermal inertia } \\ \text { ick } & \text { incremental counter keeper } \\ \text { JMARS } & \text { Java Mission-planning and Analysis Remote Sensing } \\ \text { MGD }^{3} & \text { Mars Global Digital Dune Database } \\ \text { ock } & \text { orbital counter keeper } \\ \mathrm{SI} & \text { Stability index } \\ \text { tiu } & \text { International System of Units-derived unit of thermal inertia, tiu }=\mathrm{J} \mathrm{m}^{-2} \mathrm{~K}^{-1} \mathrm{~s}^{-1 / 2} \\ \text { USGS } & \text { U.S. Geological Survey }\end{array}$

\section{Instruments}

CTX Context Camera, onboard Mars Reconnaissance Orbiter, resolution is $6 \mathrm{~m} / \mathrm{pixel}$.

HiRISE High Resolution Imaging Science Experiment, camera onboard Mars Reconnaissance Orbiter, capable of $\sim 25 \mathrm{~cm} /$ pixel

resolution.

MGS Mars Global Surveyor.

MOC Mars Orbiter Camera, onboard Mars Global Surveyor, capable of $1.5 \mathrm{~m} / \mathrm{pixel}$ resolution.

MOLA Mars Orbiter Laser Altimeter

TES Thermal Emission Spectrometer, onboard Mars Global Surveyor, footprints are $\sim 3 \mathrm{~km}$ in diameter.

THEMIS VIS THermal EMission Imaging System VISible-wavelength camera, on board the Mars Odyssey spacecraft, capable of $\sim 18 \mathrm{~m} /$ pixel resolution. 


\title{
Mars Global Digital Dune Database (MGD³)—Composition, Stability, and Thermal Inertia
}

By Amber L. Gullikson, ${ }^{1}$ Rosalyn K. Hayward, ${ }^{1}$ Timothy N. Titus, ${ }^{1}$ Heather Charles, ${ }^{2}$ Lori K. Fenton, ${ }^{3}$ Rachael H. Hoover, ${ }^{4}$ and Nathaniel E. Putzig ${ }^{5}$

\begin{abstract}
The Mars Global Digital Dune Database $\left(\mathrm{MGD}^{3}\right)$ is an online repository that has catalogued dune fields larger than $1 \mathrm{~km}^{2}$ located between latitudes $90^{\circ} \mathrm{N}$. and $90^{\circ} \mathrm{S}$. The work presented here expands upon previous $\mathrm{MGD}^{3}$ open-file reports, with a new emphasis upon characterizing dune fields through composition, stability, and thermal inertia. Included in this latest addition is a detailed compositional analysis and the associated observational data from Mars Global Surveyor (MGS) Thermal Emission Spectrometer (TES) for dune fields $300 \mathrm{~km}^{2}$ or larger; a near-global dune stability assessment; Mars Odyssey (MO1) Thermal Emission Imaging System (THEMIS) apparent thermal inertia values; and vertical near-surface thermophysical heterogeneities determined by fitting a twolayer thermal model to observed temperatures. These additional datasets are divided into two workbooks: equatorial and south polar regions. A detailed description for the layout of these workbooks can be found in the corresponding metadata document. The continuing goal of the $\mathrm{MGD}^{3}$ is to provide a reliable and multifaceted repository of data for Mars' dunes, with the intention that such data be easily accessible and useful to future research.
\end{abstract}

\section{Introduction}

In response to the influx of new data collected for dune deposits across Mars from orbital and rover missions, a comprehensive database referred to as the Mars Global Digital Dune Database $\left(\mathrm{MGD}^{3}\right.$ ) was constructed (Hayward and others, 2004). It was compiled and released in three parts as U.S. Geological Survey open-file reports, divided as follows: the north polar region (lat. $65^{\circ}-90^{\circ} \mathrm{N}$.) (Hayward and others, 2010), the equatorial region (lat. $65^{\circ}$ N.-65 $5^{\circ}$ S.) (Hayward and others, 2007), and the south polar region (lat. $65^{\circ}-90^{\circ} \mathrm{S}$.) (Hayward and others, 2012). The database contains the global distribution of medium-to-large dune fields $\left(>1 \mathrm{~km}^{2}\right)$, and includes a classification of dune morphologies, slip face measurements, and estimated dune-field sediment volumes.

\footnotetext{
${ }^{1}$ U.S. Geological Survey

${ }^{2}$ University of Arizona

${ }^{3}$ SETI Institute

${ }^{4}$ Southwest Research Institute

${ }^{5}$ Planetary Science Institute
} 


\section{New Additions to the MGD³}

Data presented in this release expands upon the previously published $\mathrm{MGD}^{3}$ open-file reports, with a goal to evaluate the roles of chemical versus mechanical weathering in the evolution of Martian dune-field sediments. This objective was addressed through three tasks: (1) quantify the mineralogy for large Martian dune fields, (2) determine whether there are spectrally discrete markers that can be used to determine a mineralogical maturity index for Martian dune sands, and (3) determine a relationship between dune-field mineralogy, stability, and thermal inertia. Thus, the three main contributions being added to $\mathrm{MGD}^{3}$ are a detailed thermal and compositional analysis for dune fields $300 \mathrm{~km}^{2}$ or larger, a dune field stability index, and results from two-component heterogeneity modeling using apparent thermal inertia (ATI). These additional datasets are divided into two separate Excel workbooks: equatorial (EQ) and south polar (SP) regions (available at https://doi.org/10.3133/ofr20181164). Both workbooks reflect the same range in latitude as previously mentioned, with the exception of the stability index data in the equatorial workbooks, which covers an area from latitudes $65^{\circ} \mathrm{S}$. to $75^{\circ} \mathrm{N}$.

\section{Thermal and Compositional Dune-Field Analysis}

The detailed thermal and compositional dune-field analysis includes observational data acquired from the Mars Global Surveyor (MGS) Thermal Emission Spectrometer (TES) (Christensen and others, 2001), which was extracted using Java Mission-planning Analysis Remote Sensing (JMARS) software (Christensen and others, 2009). Because of time limitations, data extraction and quantitative compositional modeling were confined to dune fields $300 \mathrm{~km}^{2}$ or larger, resulting in a total of 58 dune fields in the equatorial region and 51 dune fields in the south polar region. We used DaVinci, a free programming tool developed by Arizona State University (Edwards and others, 2011, 2015) in conjunction with a linear unmixing algorithm (Ramsey and Christensen, 1998; Rogers and Aharonson, 2008) to quantitatively model dune-field compositions.

\section{The Dune Field Stability Assessment}

The term stability index is used as an inferred metric of what degree a dune field's surface morphology is influenced by non-aeolian (for example, mass wasting) processes. Stability index (SI) values of 1 through 6 were assigned to each dune field, with increasing numbers indicating more signs of apparent aeolian stability (and by inference, inactivity) (table 1). For example, an SI value of 1 indicates a dune field with only aeolian features apparent, thus being potentially active; an SI value of 6 indicates an eroded and degraded dune field (that is, a sand sheet) which is inferred to be fully inactive. The classifications between latitudes $50^{\circ}$ and $90^{\circ} \mathrm{S}$. were originally based on the presence of stabilization features larger than about $30 \mathrm{~m}$, identified using Context Camera (CTX), Thermal Emission Imaging System Visible (THEMIS VIS), and Mars Orbital Camera (MOC) images (Fenton and Hayward, 2010). This contribution expands on the previous study by (1) including new stability classifications for a total of 787 dune fields in the region from latitudes $65^{\circ} \mathrm{S}$. to $75^{\circ} \mathrm{N}$. $(1,462$ dune fields in total, from lat. $75^{\circ} \mathrm{N}$. to $90^{\circ} \mathrm{S}$.), excluding the north polar ergs, and (2) expanding the classification to include additional stabilization features visible at the scale of High-Resolution Imaging Science Experiment (HiRISE) images. As with the original stability index, these features are consistent with aeolian inactivity, where a lack of sand transport allows other erosional or depositional processes to influence and even dominate dune morphology. 


\section{THEMIS ATI and two-component heterogeneity modeling}

Thermal Emission Imaging System (THEMIS) and TES data were used to investigate the thermophysical properties of 171 dune fields located between latitudes $45^{\circ}$ and $90^{\circ} \mathrm{S}$. to identify the presence of subsurface volatiles (Hoover and others, 2017, 2018). Interest in these dune fields was based on the six morphological classifications of southern hemisphere dune fields by Fenton and Hayward (2010), which in this contribution correspond with SI values 1 through 6 . A poleward trend toward apparent stability roughly correlates with the distribution of near-surface ground ice (Feldman and others, 2004; Wilson and others, 2018), indicating that subsurface water ice could stabilize dunes by inhibiting aeolian reworking (Fenton and Hayward, 2010). The 171 dune fields included in this study were chosen because their area is larger than $220 \mathrm{~km}^{2}$ and they have been classified with the highest degree of confidence by Fenton and Hayward (2010).

Table 1. Stability index definitions.

[Definitions from Fenton and Hayward (2010)]

\begin{tabular}{cll}
\hline SI & \multicolumn{1}{c}{ Dune-field type } & \multicolumn{1}{c}{ Description } \\
\hline 0 & Unclassified & $\begin{array}{l}\text { Dunes that could not be classified, generally as a result of insufficient data. } \\
\text { Dunes have identifiable forms, crisp brinks, unmuted topography. } \\
1\end{array}$ \\
2 & $\begin{array}{l}\text { Terra Cimmeria } \\
\text { Dunes partially surrounded by crisp-edged sandy aprons that do not completely } \\
\text { merge with those of neighboring dunes. }\end{array}$ \\
3 & $\begin{array}{l}\text { Smith crater } \\
\text { South Terra Cimmeria }\end{array}$ & $\begin{array}{l}\text { Dune brinks may be rounded, dunes surrounded by crisp-edged sandy aprons. } \\
\text { Dunes surrounded by crisp-edged aprons, dunes appear degraded, slip faces are } \\
\text { difficult to identify, a light-toned layer is exposed at the edge of the dune field. } \\
\text { Dunes appear highly degraded, slip faces are difficult to identify, a light-toned } \\
\text { layer is exposed at the dune-field edge and interdunes. } \\
\text { Dunes are not present, only a sandy surface is present, aprons may be present, a } \\
\text { light-toned layer is exposed at the edge. }\end{array}$ \\
\hline
\end{tabular}

\section{Purpose and Scope}

This report presents detailed information on composition, stability, and thermal inertia for dune fields located in the equatorial and south polar regions of Mars. The purpose for this new addition to the $\mathrm{MGD}^{3}$ is to continue the global characterization of Martian dune fields and assess whether mineralogic distribution, aeolian activity, and thermophysical properties are related. The datasets used in this study include the following: TES thermal inertia and surface emissivity; THEMIS ATI; and CTX, MOC, THEMIS VIS, and HiRISE images. Software used to extract and process data includes JMARS, DaVinci, and MARSTHERM.

\section{Database Organization and Terminology}

The term $\mathrm{MGD}^{3}$ refers to the entire Mars Global Digital Dune Database. When referring to a particular region, an abbreviated regional term (for example, SP for south polar) is used. The new additions to the $\mathrm{MGD}^{3}$, for both the equatorial and south polar regions, are comprised of six main categories:

- Global summary

- TES observation data summary-Thermal inertia (daytime and nighttime)

- Individual dune fields-Composition

- Individual dune fields-Track

- Stability index 
- THEMIS/TES-Thermal inertia model fits

The corresponding metadata document for this publication provides a detailed description for each of these categories and explains the layout for both the equatorial and south polar workbooks.

\section{MGD 3 Data Processing and Methodology}

\section{TES Observational Data}

We extracted TES data using JMARS (Christensen and others, 2009) for all dune fields located in the equatorial and south polar regions that were greater than or equal to $300 \mathrm{~km}^{2}$ in size (109 dune fields in total). TES collected surface data as MGS orbited Mars (Christensen and others, 2001). Therefore, TES data presented here were first categorized by the corresponding dune-field identification number (a seven-digit identification number, assigned in the MGD $^{3}$ by Hayward and others [2007, 2010, 2012] using the method of Barlow [2003] to assign identification numbers to craters), followed by the TES track number(s) (also referred to as the MGS orbital number or ock number). This section of the database comprises two sets of data labeled Daytime Thermal Inertia and Nighttime Thermal Inertia, according to the parameters used in JMARS to extract the data (table 2).

The Daytime Thermal Inertia data was compiled using two sets of specifications, labeled full parameters and relaxed parameters (table 2). The full parameter set includes only the highest quality TES observations (that is, surface data acquired when the atmosphere was clear and surface temperatures were $>250$ kelvin). Additional fields of information (for example, Lambertian albedo and local time-all listed in the metadata document) are also included to provide the most robust set of data for dune-field characterization. The second version has a more relaxed set of parameters and results in a dataset that is larger but lower in quality (for example, surface data collected when dust and [or] ice was present in the atmosphere is included).

The Nighttime Thermal Inertia dataset uses several parameters different from those in the Daytime Thermal Inertia versions (table 2). The atmospheric opacity rating, best fit opacities, and target temperature are omitted, but the local time and thermal inertia spectrometer rating are included to filter the data differently. By removing the target temperature range and constraining local time to 0 to 4 hours, this restricts the data to the portion of the night least influenced by insolation. Data that have been extracted are listed in the metadata document, and meaningful values (for example, thermal inertia spectrometer ratings) are accompanied by brief explanations.

\section{Compositional Analysis}

Endmember minerals (Rogers and Fergason, 2011, and all references therein) and mineral-group abundances (Rogers and Fergason, 2011; Ahrens and Titus, 2014) were modeled for all dune fields included in the TES observation dataset. Each modeled dune field has an individual worksheet that contains both the compositional abundances and uncertainties for each analysis. TES emissivity data were first extracted using JMARS (Christensen and others, 2009) and then processed with DaVinci (Edwards and others, 2011, 2015). An atmospheric-correction algorithm was first run to remove atmospheric endmembers based on the deconvolution method of Bandfield and others (2000a), Smith and others (2000), and Rogers and Aharonson (2008). An unmixing algorithm (Ramsey and Christensen, 1998; Rogers and Aharonson, 2008) that uses a mineral spectral library (that is, Rogers and Fergason, 2011; Ahrens and Titus, 2014) in conjunction with a non-negative least squares fitting routine (Lawson and Hanson, 1974; Christensen and others, 2001) was then run to generate a bulk mineralogy assemblage with an accuracy and detection threshold of 10-15 percent (for example, Feely and 
Christensen, 1999; Christensen and others, 2000; Bandfield, 2002; Rogers and others, 2007). Two sets of data were generated using this method: an endmember mineral assemblage comprising 44 minerals (Rogers and Fergason, 2011) and a mineral group assemblage composed of 8 mineral groups (Rogers and Fergason, 2011; Ahrens and Titus, 2014).

The TES thermal infrared interferometer subsystem (which measures the wavelength range of 6 to 50 microns, or $\sim 1,650-200 \mathrm{~cm}^{-1}$ ) is affected by several radiometric errors known to cause potential glitches in the spectra (Christensen and others, 2001; Bandfield, 2002 Pankine, 2015). One particular radiometric error that has been proposed by Pankine (2015) as a "periodic sampling error of the TES interferogram" has been identified as a time- and wavenumber-dependent error that has the greatest effect on spectral surfaces $<210 \mathrm{~K}$ and atmospheric limb-viewing geometry. Vibrations of the spacecraft is proposed as the likely cause of this issue (notably a damaged solar panel onboard the MGS) (Albee and others, 2001; Pankine, 2015) and can affect the TES spectra in a series of ways, including changing the shape of the approximately $800-1,200 \mathrm{~cm}^{-1}$ silicate absorption (Pankine, 2015; Joshua L. Bandfield, Space Science Institute, written commun., 2018). As TES spectra is modeled and unmixed this change in shape can result in the over-estimation of sulfate present on the surface and the under-estimation of feldspar (see Appendix). Researchers determined that the magnitude of this error increased significantly over the length of the MGS mission, with the error first becoming an issue after about ock number 7,000 (Bandfield, 2002; Pankine, 2015).

Using our previously listed parameters, we have collected data for every ock that covered dune fields $300 \mathrm{~km}^{2}$ in size or greater, including ock numbers greater than 7,000. Sulfate and feldspar are the main two mineral groups known to be affected by the spectral glitch, therefore, spectral unmixing for ock numbers greater than 7,000 should still provide valuable information for other mineral groups. In the equatorial and south polar workbooks there are two global summary worksheets, one that has included averaged mineral abundances for all the collected ock numbers for every dune field, and a second worksheet only including averaged mineral abundances for ock numbers less than 7,000. Provided in the Appendix are a set of graphs (figure 1.1) depicting the change in mineral abundance for each dune field when ock numbers greater than 7,000 are excluded.

\section{Stability Index}

The presence or absence of several specific features visible in THEMIS VIS images (larger than $\sim 30 \mathrm{~m}$ in size) are used to determine which of the six stability indices (table 1, fig. 1) each dune field best fits, corresponding with previous dune-field classifications (Fenton and Hayward, 2010). In the case of dune fields corresponding with those in the South Polar MGD 3 (Hayward and others, 2012), these classifications should be regarded as an update on the previous entry in Fenton and Hayward (2010), as new images permitted a higher confidence of classification. Because this classification is conducted subjectively, a confidence parameter is also included: a value of 1 indicates a highly confident morphological classification, 2 indicates a somewhat confident morphological classification, and 3 indicates a less confident morphological classification. All high-quality images of each dune field were inspected to determine the most appropriate stability index. 
Table 2. Data selection parameters for Thermal Emission Spectrometer (TES) data.

[Detailed descriptions of each field name/parameter are located under the "Tracks" section of the metadata document.]

\begin{tabular}{lcccccc}
\hline \multirow{2}{*}{ Field name } & \multicolumn{2}{c}{$\begin{array}{c}\text { Daytime full } \\
\text { parameters }\end{array}$} & \multicolumn{2}{c}{$\begin{array}{c}\text { Daytime relaxed } \\
\text { parameters }\end{array}$} & \multicolumn{2}{c}{ Nighttime parameters } \\
\cline { 2 - 7 } & Min & Max & Min & Max & Min & Max \\
\hline Length of scan & 1 & 1 & 1 & 1 & 1 & 1 \\
Spatial detector mask & 7 & 7 & 7 & 7 & 7 & 7 \\
Spectral mask & 0 & 0 & 0 & 0 & 0 & 0 \\
Emission angle & 0 & 5 & 0 & 5 & 0 & 5 \\
Atmospheric opacity rating & 0 & 0 & 0 & 1 & - & - \\
Best fit opacity (1) & 0 & 0.2 & 0 & $0.16^{*}$ & - & - \\
Best fit opacity (2) & 0 & 0.1 & 0 & $0.05^{*}$ & - & - \\
Target temperature (K) & 250 & 340 & 250 & 340 & - & - \\
Phase inversion & 0 & 0 & 0 & 0 & 0 & 0 \\
Risk of algorithm phase & 0 & 0 & 0 & 0 & 0 & 0 \\
$\quad$ inversion & & & & & & 0 \\
Number of image motion & 0 & 0 & 0 & 0 & 0 & 0 \\
$\quad$ compensation steps & - & - & - & - & 0 & 3 \\
$\begin{array}{l}\text { Thermal inertia } \\
\text { spectrometer rating }\end{array}$ & - & - & - & - & 0 & 4 \\
Local time & - & &
\end{tabular}

*Values were initially collected as total dust and total ice, and then converted to best fit opacity values using the equation: $\ln (1 /(1-$ total ice $))$ (when calculating for total dust, total ice will be replaced with total dust value). The surface radiance that TES collects can be inhibited by the amount of dust and ice in the atmosphere. Therefore, by using apparent emissivity spectra from surface types 1 and 2, hematite, and atmospheric endmembers in a least squares fitting algorithm, values for total dust and ice in the atmosphere can be estimated (Bandfield and others, 2000b; Smith and others, 2000). Converting total dust and total ice to best fit opacities does result in a more restrictive range than what is used in the full parameters. However, relaxing the atmospheric opacity parameter to include spectra with a rating of 1 results in a larger dataset.

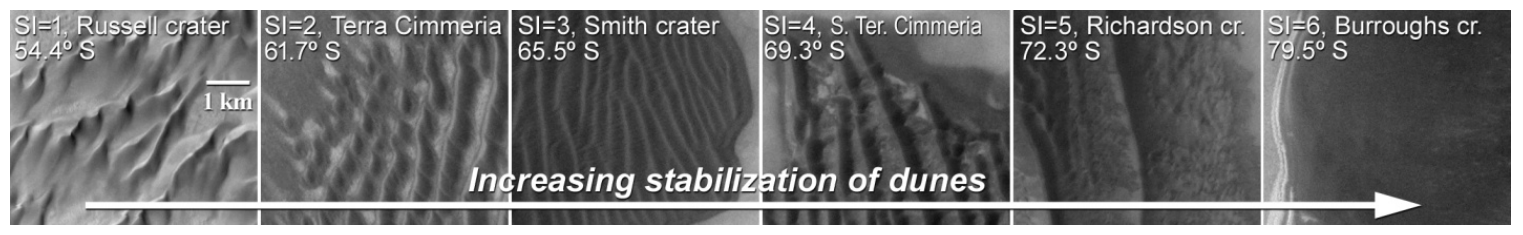

Figure 1. THEMIS VIS images of dune fields exhibiting the six stability index (SI) morphological categories inferred to correspond with stability, ranging from zero stabilization $(S \mid=1)$ to complete dune-field degradation (SI=6). S., south; Ter., Terra; cr., crater. 

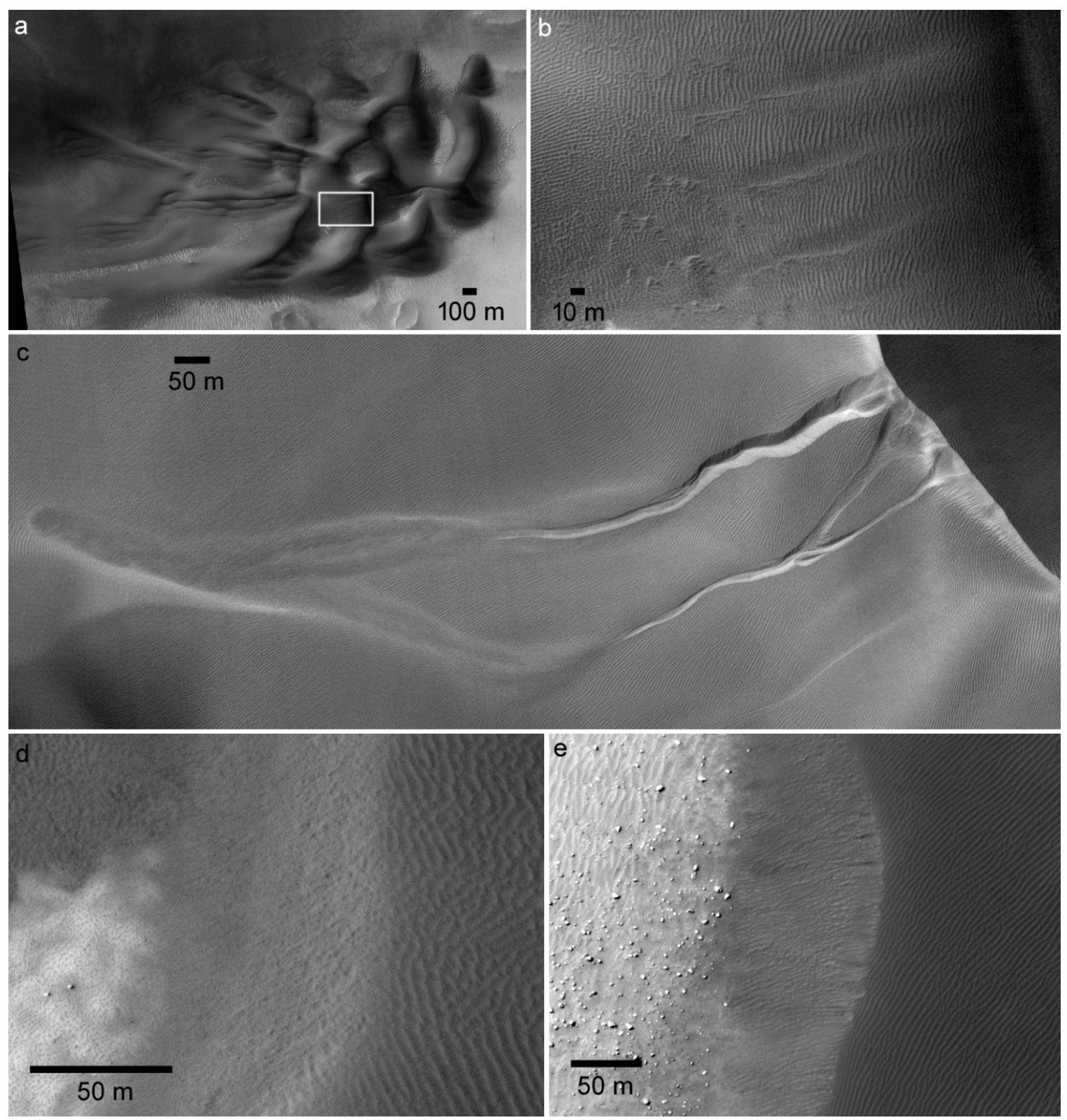

Figure 2. HiRISE images showing examples of non-aeolian features forming on dunes, including $A$ and $B$ (white box in A), pole-facing lineaments (HiRISE ESP_016063_1260); C, dune gullies (HiRISE ESP_022471_1300); $D$, pitted surface on a slip face adjacent to a rippled stoss slope (HiRISE ESP_039514_1200); and E, small masswasting alcoves at the top of a dune slip face (HiRISE ESP_022912_1250).

The presence or absence of other features visible mainly in HiRISE images (some of which are smaller than $\sim 10 \mathrm{~m}$ ) can provide additional insight into recent aeolian activity in dune fields. Four common features were identified: a, pole-facing lineaments; $b$, gullies; $c$, small pits; and d, masswasting features. In this data attribute, the presence of each of these features at any location in a dune field is indicated by the corresponding letter (a through d). Many dune fields contain more than one type of feature; all are listed (for example, "bc" for dune fields with both gullies and small pits).

Pole-facing lineaments are quasi-horizontal parallel lines about $100 \mathrm{~m}$ apart and up to kilometers in length that form only on pole-facing slopes of southern midlatitude dunes (fig. $2 A, B$ ). Gullies are 
kilometer-scale mass-wasting features found on broad, steep dune slopes, consisting of an alcove of missing material near dune crests, a sinuous channel morphology, and an accumulation of material downslope (fig. 2C). Small pits are 1-2 $\mathrm{m}$ holes found on degraded dune surfaces, where ripples or slipface structures would otherwise be found (fig. 2D). Mass-wasting features are found on dune slip faces and include both kilometer-scale straight-channeled grooves and simple slope-failure features on slip faces (fig. 2E); neither feature is considered a "Martian gully". We interpret each of these four feature classes to be formed by a non-aeolian process that erodes the dunes and likely competes with aeolian dune-forming processes. A greater presence of these features is therefore consistent with relative dune stability. Identification of these features is dependent on image coverage, which is limited by the presence and positioning of HiRISE images, seasonal lighting, and dune-field size (for example, larger dune fields are often better targeted for imaging and present more surfaces that may exhibit these features) and slope azimuths (for example, pole-facing lineaments are only found on dunes with steep pole-facing slopes). Thus, the lack of an entry for this attribute does not necessarily indicate the feature is not present, but rather that it was not identified in images of that dune field.

\section{THEMIS ATI and TES Dune Modeling}

Thermophysical properties of 171 of the largest dune fields in the southern hemisphere were analyzed to understand and classify near-surface properties using both THEMIS infrared (100 m/pixel) (Christensen and others, 2004) and TES ( $\sim 3 \mathrm{~km} /$ pixel) data (Christensen and others, 2001). The ATI values (that is, calculations from single observations) were derived from THEMIS images to assess small-scale variations of thermophysical properties throughout each dune field. THEMIS data were also used to evaluate whether noticeable trends in grain-size distribution were present within and between dune fields. Daytime thermal inertia measurements are less accurate and, therefore, less effective at distinguishing subtle differences in materials compared to nighttime thermal inertia. Accordingly, THEMIS analyses are limited to only nighttime observations (Christensen and others, 2004). Adhering to the methods of Putzig and others (2014), brightness temperatures were calculated from THEMIS radiance values and then used to derive a best-fit ATI value. THEMIS images were processed using MARSTHERM, a publicly accessible online tool (http://marstherm.psi.edu) to create images displaying the ATI data. In addition to the image, MARSTHERM also includes a quality flag value that is based on the interpolation accuracy of each temperature value within a lookup table. High quality flag values (that is, >3) indicate inaccurate results, and such cases were excluded from this study. ATI images were then imported into Esri's ArcGIS software so dune fields could be quantitatively assessed to determine the ATI range within each dune field.

The second type of thermophysical analysis used in this portion of the study included TES data and thermal modeling. These data were used to assess the types of material present in dune fields, including subsurface volatiles, and to identify horizontal and vertical mixing or layering. TES-derived ATI values were compared with results from two-layer heterogeneity models to identify thermal signatures consistent with the presence of subsurface water ice within a dune field and to identify trends of surface materials between dune fields. TES-derived ATI data typically exhibit diurnal and seasonal variations. Comparing TES-derived ATI data with results from two-component heterogeneity models that were created for a variety of materials (for example, dust, sand, duricrust, and 'rock', where rock is thermally indistinguishable from ice and ice-cemented soil) allows one to test for possible layering or sub-pixel horizontal mixtures (Putzig and Mellon, 2007). Because of the range of thermal skin depth of the modeled materials, this analysis is limited to the top few to tens of centimeters below the surface. TES-derived ATI values at the 2 a.m. and 2 p.m. TES local observation times were compared with 
modeled values. These times are ideal because the nighttime and daytime temperature contrasts between materials of different thermophysical properties are near their maxima (Putzig and Mellon, 2007).

\section{Results}

\section{Compositional Analysis}

TES data analyses and compositional modeling were carried out for 58 dune fields in the equatorial region and 51 in the south polar region (fig. 3). Our modeling efforts resulted in identifying four main mineral groups present in large-scale dune fields: feldspar, olivine, high-silica phase (for example, opal and [or] silica glass), and sulfate, which were present at more than 10 percent abundance (fig. 4). The distribution of these minerals reflects a possible trend in either locally or regionally derived sediment sources rather than a global mineral distribution. Scattered globally with varying abundances, feldspar and olivine do not demonstrate a generalized trend in distribution. Sulfate and high-silica phases, on the other hand, appear to have a broad correlation with high southern latitudes; as latitude increases poleward beyond latitude $45^{\circ} \mathrm{S}$., sulfate and high-silica phases also increase in abundance. A similar trend has been observed in dune fields located in the north polar regions of Mars, where higher abundances of gypsum have been identified (Langevin and others, 2005; Fishbaugh and others, 2007; Tanaka and Hayward, 2008; Horgan and others, 2009), as well as an increase in high-silica phases across the northern plains (Horgan and Bell, 2012).

The presence of hematite, quartz, carbonate, and pyroxene were also identified (and included in the database), however they were not depicted in Mars global mineral distribution maps (for example, fig. 4). Hematite and quartz were only detected in small quantities (that is, below the detection threshold of 10 percent), resulting in a low level of confidence in mineral identification. Pyroxene is ubiquitous in all dune fields; endmember minerals in the model included diopside and augite (both high-calcium pyroxene) and pigeonite and bronzite (both low-calcium pyroxene). However, when data was generated for mineral group abundances, high- and low-calcium pyroxene were both placed in the generalized pyroxene mineral group. Spatial variations in pyroxene abundance could either reflect a global trend or re-confirm a regional or local sediment source trend, although, to test this notion the pyroxene group would need to be separated into low-calcium pyroxene and high-calcium pyroxene groups. Lastly, carbonate is also ubiquitous in modeled results for dune fields and falls under the abundance detection limit, though the reasoning for this slightly differs from previously mentioned explanations. Much of the TES spectra analyzed here have a low emissivity feature at wavelengths beyond 19.3 micrometers $(\mu \mathrm{m})$ (atmospheric $\mathrm{CO}_{2}$ absorption occurs between 12.3 and $19.3 \mu \mathrm{m}$ and is therefore removed during the atmospheric correction step in DaVinci). Currently the only mineral group identified thus far that shares this similar dip in emissivity is carbonate, and as a result DaVinci uses carbonate ubiquitously in the model fit (Bandfield and others, 2003). Therefore, carbonate may in fact be present in minor amounts where TES footprints are, or there is a mineral that has yet to be identified and included in the spectral library. The modeled mineral abundance for carbonate has been included in the database, although values may be suspect for this reason.

\section{Stability Index}

The stability index assessment covers Mars from latitudes $75^{\circ} \mathrm{N}$. to $90^{\circ} \mathrm{S}$. and includes a total of 1,462 dune fields (fig. 6). In assessing the global distribution of apparent aeolian activity on Martian dune fields, our results re-confirmed the conclusion by Fenton and Hayward (2010) that dune-field stability correlates strongly with latitude. Dune fields from the high northern latitudes to the mid 
southern latitudes depict no features associated with dune-field stability and are inferred to be active (classified as SI 1). In contrast, with increasing poleward latitudes in the southern hemisphere, features indicative of stability and inactivity are increasingly prevalent. An interesting finding is that the progression toward inferred stability in the southern hemisphere is not repeated in the northern hemisphere. A few dune fields at high northern latitudes have tentatively been classified with an SI value of 2 but features initially used to identify stability in the high southern latitudes are rare elsewhere. As with many other features recording climate change on Mars, dune morphology is starkly different between the high northern and high southern latitudes.

Similar to results from mapping of stability index features, other stability-related features are also more common at high southern latitudes than elsewhere on Mars (fig. 7). Pole-facing lineaments peak in density between latitudes $50^{\circ}$ and $55^{\circ} \mathrm{S}$., and gullies peak slightly equatorward of this at latitudes $45^{\circ}-50^{\circ} \mathrm{S}$. Pitted surfaces are found in nearly every dune field between latitudes $60^{\circ}$ and $65^{\circ}$ $\mathrm{S}$. and are only occasionally found between latitudes $40^{\circ}$ and $60^{\circ} \mathrm{S}$. Mass-wasting features, particularly small slip-face slope failures, are most common from latitudes $40^{\circ}$ to $50^{\circ} \mathrm{S}$., and are the only stabilityrelated features found at other latitudes on Mars, both near the equator and in the northern hemisphere. The presence of these mass-wasting features at low latitudes may not indicate the presence of ice, but rather some other competence-inducing agent (for example, precipitated salt).

The modeled mineral abundances and their locations (fig. 4), as well as averaged albedo and nighttime thermal inertia values (fig. 5) were compared to the observed stability index trends (fig. 6) with the goal of determining whether mineral composition/abundance is a viable mechanism for the detection of sediment maturity in deposits of saltated sand (for example, dune fields). Because stability increases towards the south pole, mineral distribution was also analyzed for similar trends. Apart from a general increase in abundance for high-silica phases and sulfate as latitude increases southward, the distribution of these minerals and their abundance does not directly correlate with stability. For example, not all dune fields south of latitude $45^{\circ} \mathrm{S}$. have high abundances of sulfate and (or) high-silica phases, and dune fields with an increased volume of these minerals does not always have a high stability index value. As a result, there is no obvious candidate mineral indicative of global-scale mineral maturity; further investigations at the scale of individual dune fields may prove more fruitful.

\section{THEMIS ATI and TES Dune Modeling}

A total of 51 dune fields (of the 171 analyzed) were investigated using THEMIS data (some were not included owing to error or processing issues). Three characteristic ATI value distributions were identified within dune fields: (1) the dune-field edge and crest have higher ATI than the surrounding materials; (2) the entire dune field has a lower ATI than the surrounding material; or (3) no discernable pattern is observed. Trends in stability and THEMIS ATI and trends in stability and 2-layer TES heterogeneity models were also discerned. Dune fields classified as SI 4 and SI 5 typically have lower ATI than surrounding materials but lack observable patterns within the dune fields. SI 1 dune fields (that is, potentially active dune fields) and SI 2 dune fields (that is, potentially active dune fields with partial aprons) primarily matched 'crust over dust' models, whereas SI 6 dune fields (that is, sand sheets) generally matched models with a rock/ice thermal signature. 


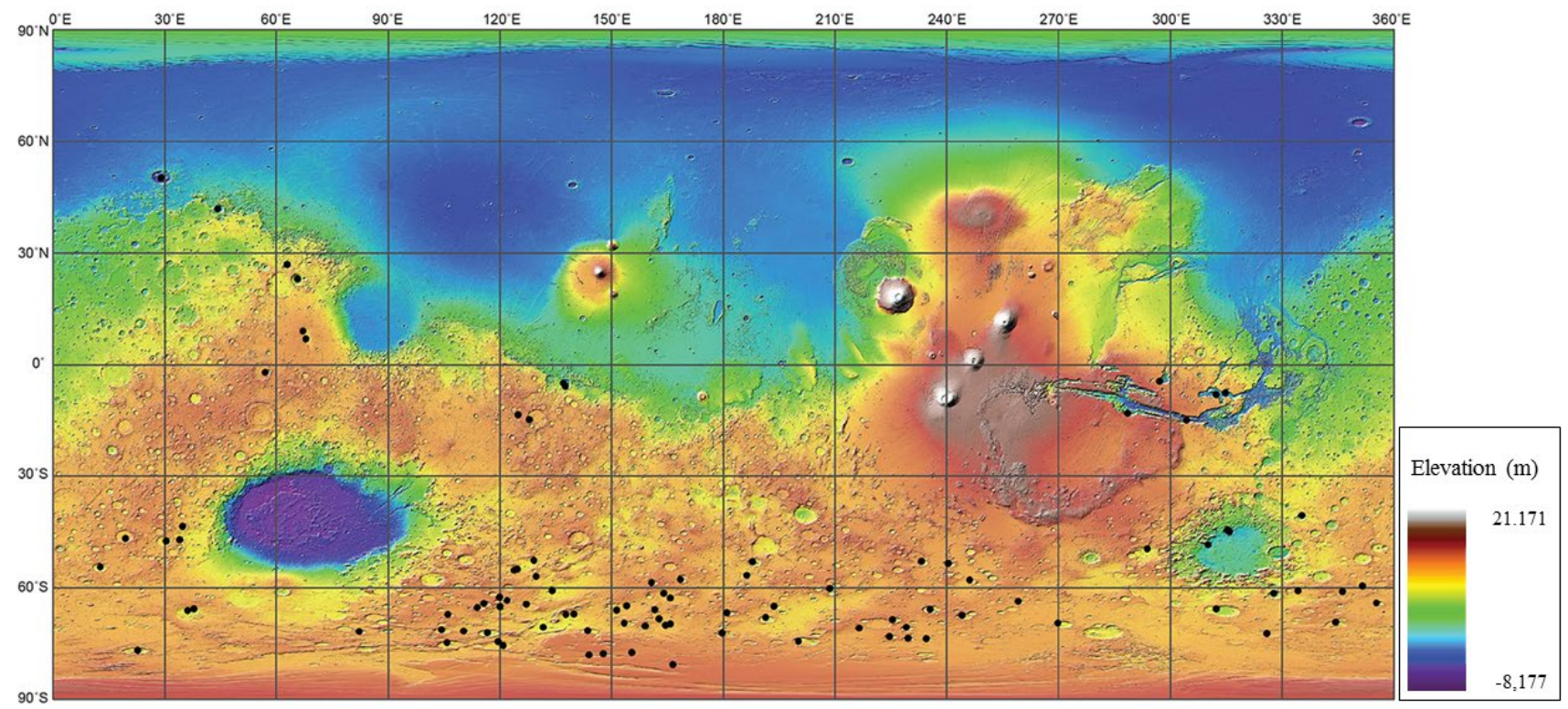

Figure 3. Mars Orbiter Laser Altimeter (MOLA) global shaded relief map of Mars topography showing dune fields included in the compositional analysis (black dots). 

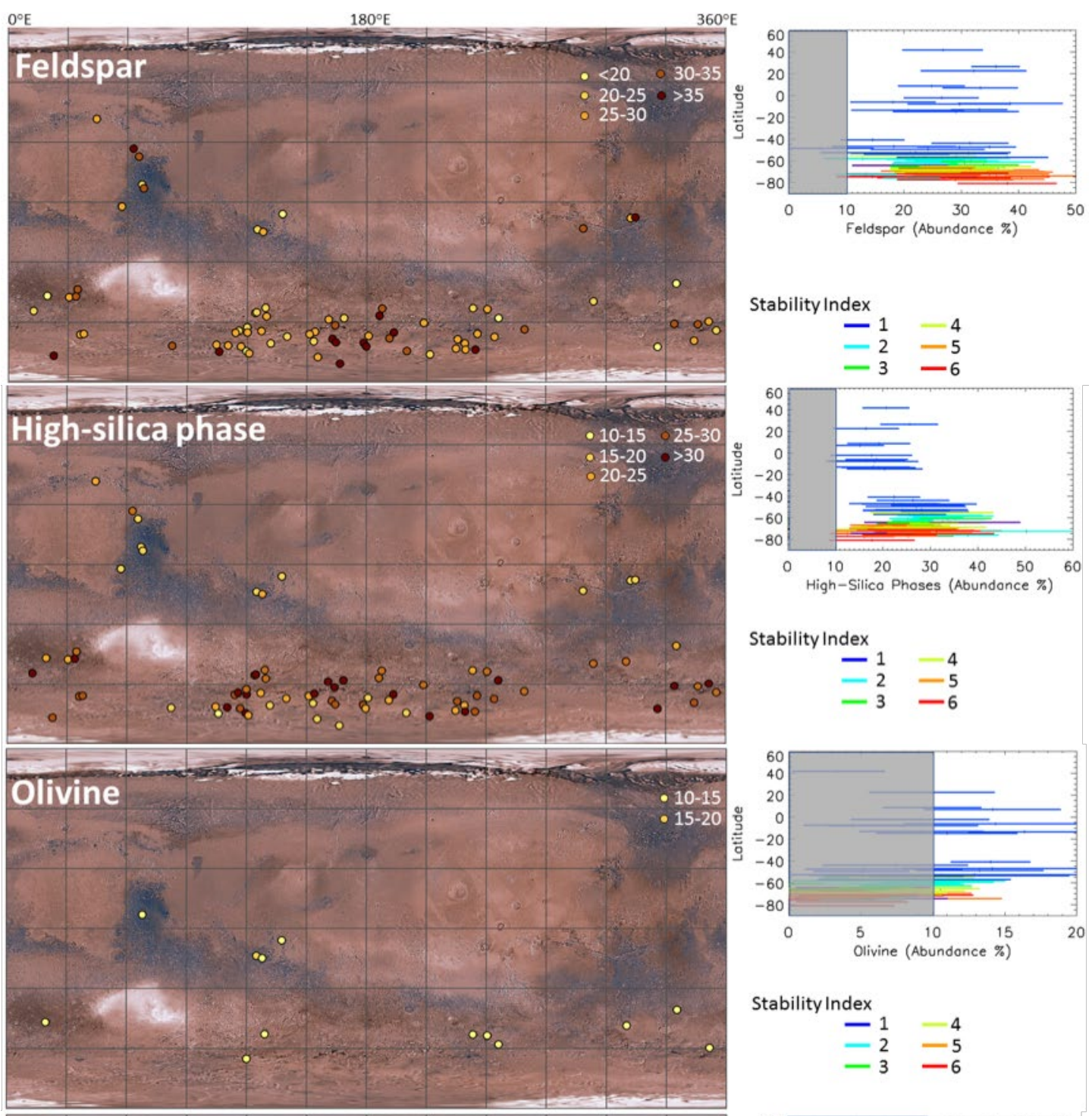

Stability Index

$$
\begin{array}{ll}
-1 & -4 \\
-2 & -5 \\
-3 & -6
\end{array}
$$
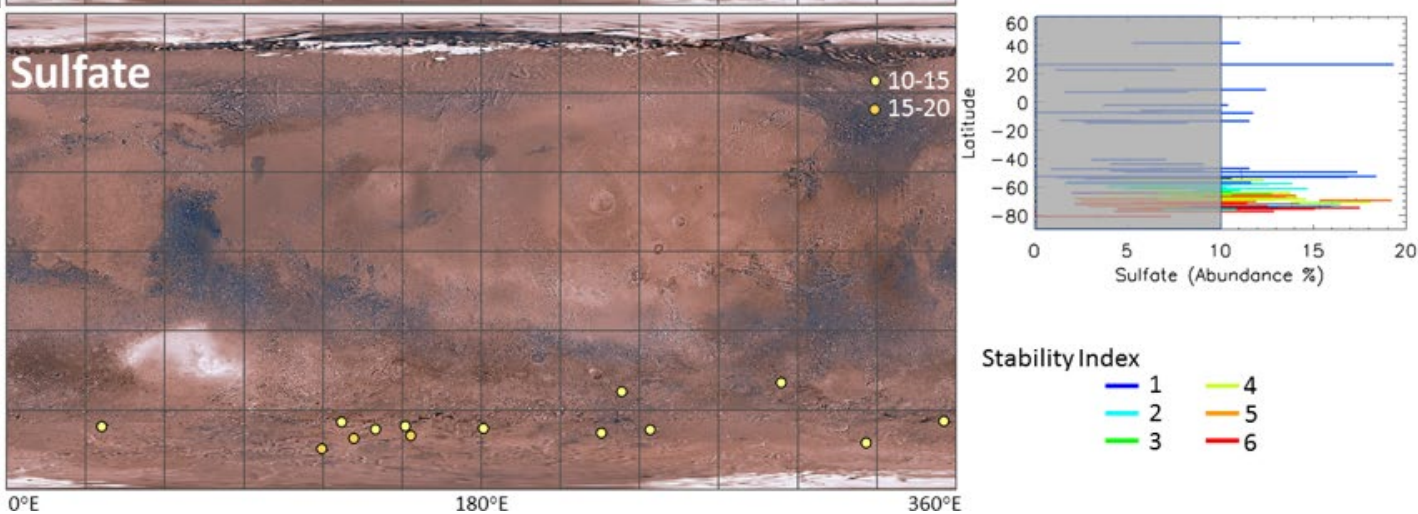

Stability Index

$$
\begin{array}{ll}
-1 & -4 \\
-2 & -5 \\
-3 & -6
\end{array}
$$

Figure 4. Global albedo maps of Mars showing locations of dune fields (colored circles) and their corresponding mineral abundances (in percent) for only ock numbers less than 7,000. Data displayed on the maps only include mineral abundances that are above the detection limit threshold (10 percent abundance). The associated mineral graphs are plotted along each dune field's latitude location and color corresponds to its stability index. Graphs include error bars for all modeled data and gray boxes overlay values that are below the detection threshold. 

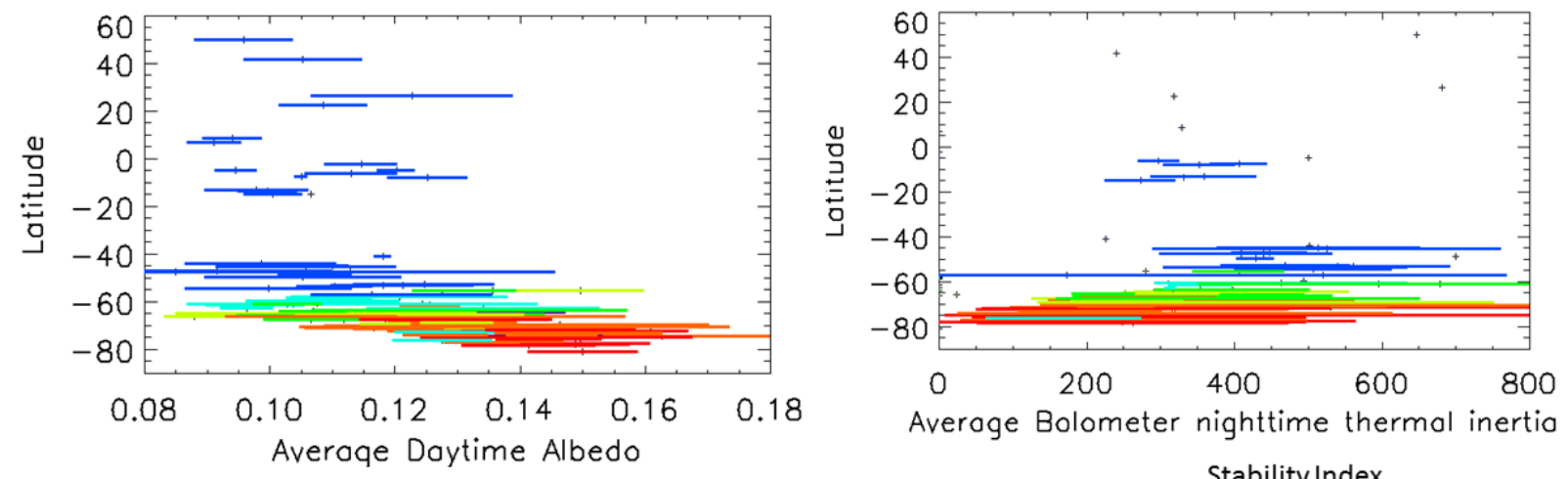

Stability Index

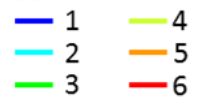

Figure 5. Plots showing latitude of dune fields used in the compositional analysis (for all ock numbers, including those greater than 7,000 ) versus averaged albedo (left) and averaged nighttime thermal inertia derived values (in tiu) from the thermal emission spectrometer (TES) thermal infrared bolometer (right). Color corresponds to the dune field's assigned stability index and bars represent the standard deviation of the data. Plus signs represent single data points, therefore, error bars could not be calculated.

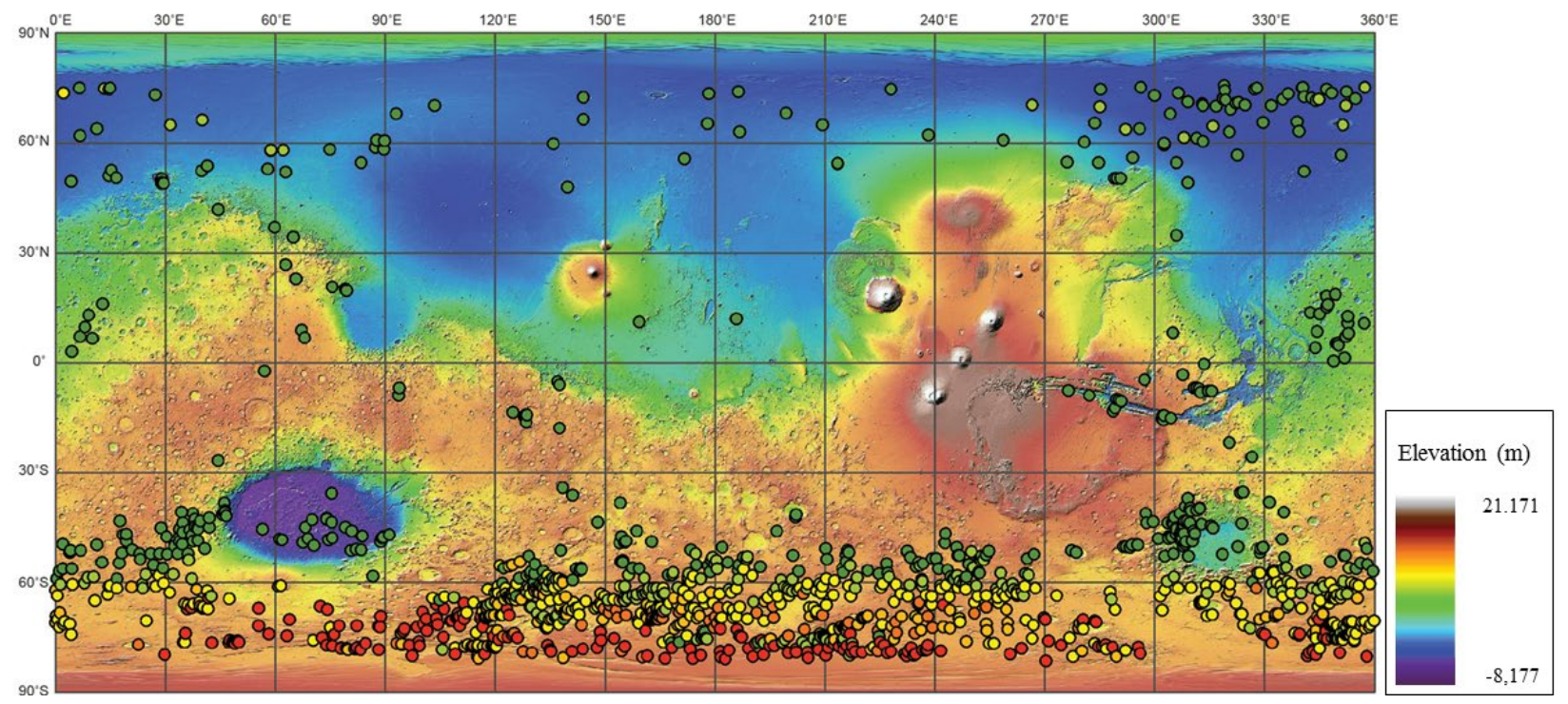

Figure 6. Mars Orbiter Laser Altimeter (MOLA) global shaded relief map of Mars topography showing dune-field locations included in the stability assessment (circles). Circle colors indicate assigned stability index class of dune field: green, 1; light green, 2; yellow, 3; light orange, 4; orange, 5; red, 6. 


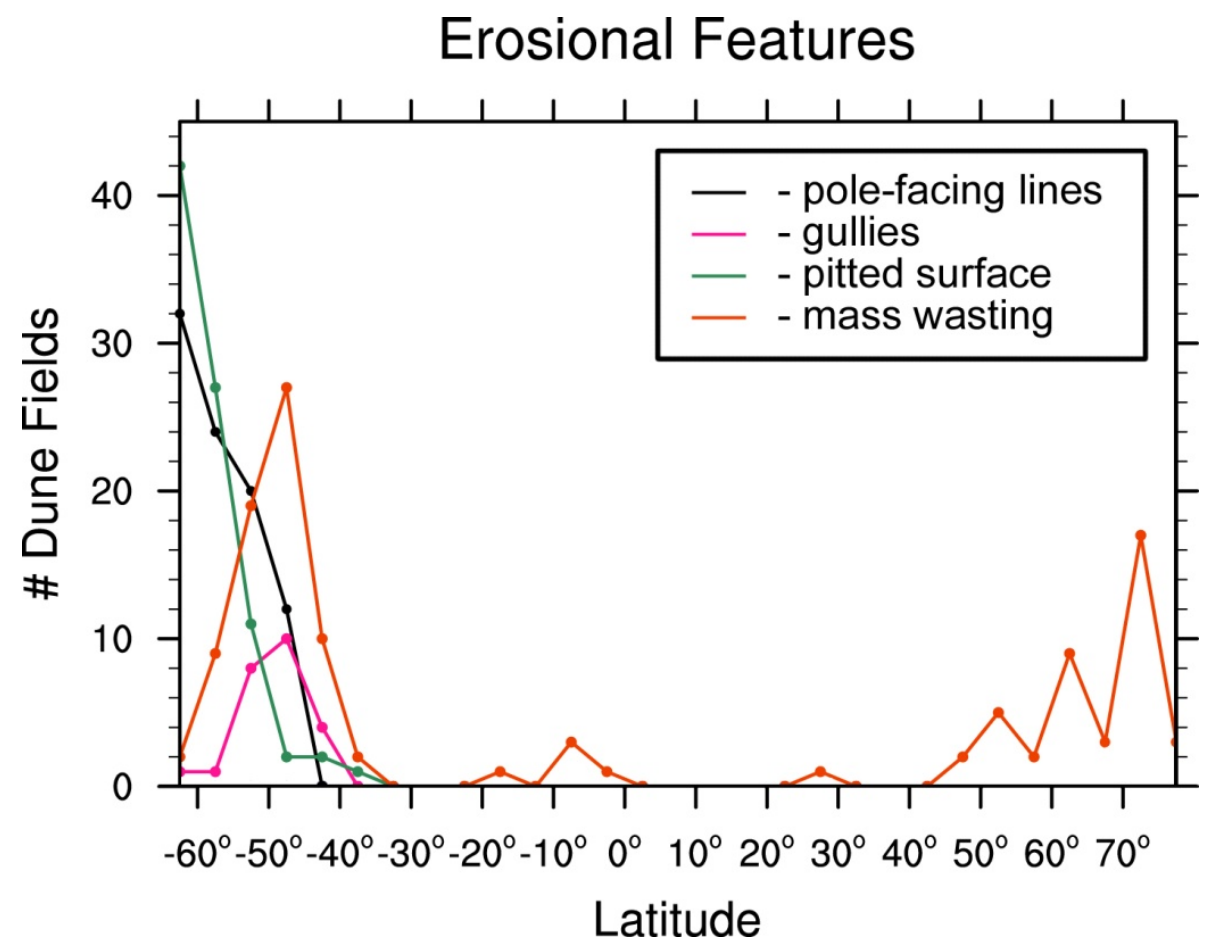

Figure 7. Plot showing the latitudinal distribution of smaller-scale stability features visible in HiRISE images.

\section{Summary}

The surface of modern Mars is active. Aeolian processes transport and possibly alter surface sediment. Dune fields provide a record of these and past processes. Mineral composition, stability, and thermal inertia estimates are important resources that can be used in the reconstruction of the environmental and climatic history of Mars. Data released in this report comprises a detailed thermal and mineralogical analysis for large-scale dune fields, a near-global stability assessment of dune fields, and a two-component heterogeneity model using ATI.

The extent of aeolian activity on a dune field is heavily influenced by its latitudinal location. Dune fields located in the high northern latitudes and extending down to the mid southern latitudes display morphologic features characteristic of aeolian processes, whereas closer to the south pole (that is, higher southern latitudes) display features indicative of mass wasting (increasing inactivity), with potential rock/ice thermal signatures. The degree in which a dune field exhibits stabilization features (its stability index) does not, however, directly correlate to a dune field's mineralogy. Compositional modeling results determined that there is an increase in high-silica phases and sulfate in southern latitudes greater than $45^{\circ} \mathrm{S}$., though neither mineral is distributed uniformly across the southern hemisphere or is necessarily associated with a high stability index. Therefore, no mineral identified thus far is an ideal candidate for a mineral maturity index. By quantifying large-scale dune-field mineral abundances, we have also concluded that a dune field's mineralogy is likely representative of a local or regional sediment source, rather than a uniform global distribution. 


\section{References Cited}

Ahrens, C.J., and Titus, T.N., 2014, An assessment of the reliability of mineral abundance estimates derived from TES data over dune sites [abs.]: 8th International Conference on Mars Program and abstracts, abstract no. 1012.

Albee, A.L., Arvidson, R.E., Palluconi, F., and Thorpe, T., 2001, Overview of the Mars Global Surveyor mission: Journal of Geophysical Research, v. 106, no. E10, p. 23291-23316.

Bandfield, J.L., 2002, Global mineral distributions on Mars: Journal of Geophysical Research, v. 107, no. E6, 7 p.

Bandfield, J.L., Christensen, P.R., and Smith, M.D., 2000b, Spectral data set factor analysis and endmember recovery-Application to analysis of Martian atmospheric particulates: Journal of Geophysical Research, v. 105, no. E4, p. 9573-9587.

Bandfield, J.L., Glotch, T.D., and Christensen, P.R., 2003, Spectroscopic identification of carbonate minerals in the Martian dust: Science, v. 301, no. 5636, p. 1084-1087.

Bandfield, J., Hamilton, V.E., and Christensen, P.R., 2000a, A Global View of Martian Surface Compositions from MGS-TES: Science, v. 287, pp. 1626-1630.

Barlow, N.G., 2003, Revision of the "Catalog of large Martian impact craters" [abs.]: 6th International Conference on Mars Program and abstracts, abstract no. 3073.

Christensen, P.R., Bandfield, J.L., Hamilton, V.E., Howard, D.A., Lane, M.D., Piatek, J.L., Ruff, S.W., and Stefanov, W.L., 2000, A thermal emission spectral library of rock-forming minerals: Journal of Geophysical Research, v. 105, no. E4, p. 9735-9739.

Christensen P.R., Bandfield, J.L., Hamilton, V.E., Ruff, S.W., Kieffer, H.H., Titus, T.N., Malin, M.C., Morris, R.V., Lane, M.D., Clark, R.L., Jakosky, B.M., Mellon, M.T., Pearl, J.C., Conrath, B.J., Smith, M.D., Clancy, R.T., Kuzmin, R.O., Roush, T., Mehall, G.L., Gorelick, N., Bender, K., Murray, K., Dason, S., Greene, E., Silverman, S., and Greenfield, M., 2001, Mars Global Surveyor Thermal Emission Spectrometer experiment-Investigation description and surface science results: Journal of Geophysical Research, v. 106, no. E10, p. 23,823-23,871

Christensen, P.R., Jakosky, B.M., Kieffer, H.H., Malin, M.C., McSween, H.Y., Nealson, K., Mehall, G.L., Silverman, S.H., Ferry, S., Caplinger, M., Ravine, M., 2004, The Thermal Emission Imaging System (THEMIS) for the Mars 2001 Odyssey Mission: Space Science Reviews, v. 110, no. 1-2, p. $85-130$.

Christensen, P.R., Engle, E., Anwar, S., Dickenshied, S., Noss, D., Gorelick, N., Weiss-Malick, M., 2009, JMARS - A planetary GIS [abs]: American Geophysical Union, Fall Meeting 2009 Abstracts, abstract no. IN22A-06. [Available at http://abstractsearch.agu.org/meetings/2009/FM/IN22A06.html.]

Edwards, C.S., Nowicki, K.J., Christensen, P.R., Hill, J., Gorelick, N., and Murray, K., 2011, Mosaicking of global planetary image datasets - 1, Techniques and data processing for Thermal Emission Imaging System (THEMIS) multi-spectral data: Journal of Geophysical Research, v. 116, no. E10, 21 p.

Edwards, C.S., Anwar, S., Hagee, W., Doerres, D., Dickensheid, S., Christensen, P.R., 2015, Processing and visualizing planetary data using DaVinci-Updates for portability and scriptable execution [abs.]: 2d Planetary Data Workshop Program and Abstracts, abstract no. 7032.

Feely, K.C., and Christensen, P.R., 1999, Quantitative compositional analysis using thermal emission spectroscopy-Application to igneous and metamorphic rocks: Journal of Geophysical Research, $\mathrm{V}$. 104, no. E10, p. 24195-24210.

Feldman, W.C., Ahola, K., Barraclough, B.L., Belian, R.D., Black, R.K., Elphic, R.C., Everett, D.T., Fuller, K.R., Kroesche, J., Lawrence, D.J., Lawson, S.L., Longmire, J.L., Maurice, S., Miller, M.C., 
Prettyman, T.H., Storms, S.A., and Thornton, G.W., 2004, Gamma-Ray, Neutron, and Alpha-Particle Spectrometers for the Lunar Prospector mission: Journal of Geophysical Research, v. 109, no. E7, 19 p.

Fenton, L.K., and Hayward, R.K., 2010, Southern high latitude dune fields on Mars-Morphology, aeolian inactivity, and climate change: Geomorphology, v. 121, no. 1-2, p. 98-121.

Fishbaugh, K.E., Poulet, F., Chevrier, V., Langevin, Y., and Bibring, J.P., 2007, On the origin of gypsum in the Mars north polar region: Journal of Geophysical Research, v. 112, no. E7, 17 p. Hayward, R.K., Titus, T.N., Mullins, K.F., Fenton, L.K., Bourke, M., and Christensen, P.R., 2004, Mars Digital Dune Database [abs.]: American Geophysical Union, Fall Meeting 2004 Abstracts, abstract no. P31B-0984. [Available at http://abstractsearch.agu.org/meetings/2004/FM/P31B-0984.html]. Hayward, R.K., Fenton, L.K., Tanaka, K.L., Titus, T.N., Colaprete, A., and Christensen, P.R., 2010, Mars Global Digital Dune Database; MC-1: U.S. Geological Survey Open-File Report 2010-1170. [Available at https://pubs.usgs.gov/of/2010/1170/.]

Hayward, R.K., Mullins, K.F., Fenton, L.K., Hare, T.M., Titus, T.N., Bourke, M.C., Colaprete, A., and Christensen, P.R., 2007, Mars Global Digital Dune Database; MC2-MC29: U.S. Geological Survey Open-File Report 2007-1158. [Available at http://pubs.usgs.gov/of/2007/1158/.]

Hayward, R.K., Fenton, L.K., Titus, T.N., Colaprete, A., and Christensen, P.R., 2012, Mars Global Digital Dune Database; MC-30: U.S. Geological Survey Open-File Report 2012-1259, pamphlet 8 p. and GIS data, scale 1:20,000,000. [Available at http://pubs.usgs.gov/of/2012/1259/.]

Hoover, R.H., Putzig, N.E., Fenton, L.K., and Courville, S., 2017, Thermophysical characterization of southern hemisphere dunes on Mars [abs.]: 5th International Planetary Dunes Workshop Program and Abstracts, abstract no. 3063.

Hoover, R.H., Robbins, S.J., Putzig, N.E., Fenton, L.K., Hayward, R., Riggs, J., and Courville, S., 2018, Examining thermal inertia of layered ejecta craters and southern hemisphere dunes on Mars [abs.]: 49th Lunar and Planetary Science Conference Program and Abstracts, abstract no. 1811.

Horgan, B.H., Bell, J.F., III, Noe Dobrea, E.Z., Cloutis, E.A., Bailey, D.T., Craig, M.A., Roach, L.H., and Mustard, J.F., 2009, Distribution of hydrated minerals in the north polar region of Mars: Journal of Geophysical Research, v. 114, no. E1, 27 p.

Horgan, B., and Bell, J.F., III, 2012, Widespread weathered glass on the surface of Mars: Geology, v. 40, no. 5, p. 391-394.

Langevin, Y., Poulet, F., Bibring, J.P., and Gondet, B., 2005, Sulfates in the north polar region of Mars detected by OMEGA/Mars Express: Science, v. 307, p. 1584-1586.

Lawson, C.L., and Hanson, R.J., 1974, Solving Least-Squares Problems: Englewood Cliffs, N.J., Prentice Hall, 340 p.

Pankine, A.A., 2015, The nature of the systematic radiometric error in the MGS TES spectra: Planetary and Space Science: v. 109-110, p. 64-75.

Putzig, N.E., and Mellon, M.T., 2007, Apparent thermal inertia and the surface heterogeneity of Mars: Icarus, v. 191, p. 68-94.

Putzig, N.E., Mellon, M.T., Herkenhoff, K.E., Phillips, R.J., Davis, B.J., Ewer, K.J., Bowers, L.M., 2014, Thermal behavior and ice-table depth within the north polar erg of Mars: Icarus, v. 230, p. 6476.

Ramsey, M.S., and Christensen, P.R., 1998, Mineral abundance determination-Quantitative deconvolution of thermal emission spectra: Journal of Geophysical Research, v. 103, no. B1, p. 577596. 
Rogers, A.D., and Aharonson, O., 2008, Mineralogical composition of sands in Meridiani Planum determined from Mars Exploration Rover data and comparison to orbital measurements: Journal of Geophysical Research, v. 113, no. E6, 19 p.

Rogers, A.D., and Fergason, R.L., 2011, Regional-scale stratigraphy of surface units in Tyrrhena and Iapygia Terrae, Mars - Insights into highland crustal evolution and alteration history: Journal of Geophysical Research, v. 116, no. E8, 24 p.

Rogers, A.D., Bandfield, J.L., and Christensen, P.R., 2007, Global spectral classification of Martian low-albedo regions with Mars Global Surveyor Thermal Emission Spectrometer (MGS-TES) data: Journal of Geophysical Research, v. 112, no. E2, 29 p.

Smith, M.D., Bandfield, J.L., and Christensen, P.R., 2000, Separation of atmospheric and surface spectral features in Mars Global Surveyor Thermal Emission Spectrometer (TES) spectra: Journal of Geophysical Research, v. 105, no. E4, p. 9589-9607

Tanaka, K.L., and Hayward, R.K., 2008, Mars north circum-polar dunes-Distribution, sources, and migration history [abs]: 1st Planetary Dunes Workshop-A record of climate change, Lunar Planetary Institute, abstract no. 7012.

Wilson, J.T., Eke, V.R., Massey, R.J., Elphic, R.C., Feldman, W.C., Maurice, S., Teodoro, L.F.A., 2018, Equatorial locations of water on Mars-Improved resolution maps based on Mars Odyssey Neutron Spectrometer data: Icarus, v. 299, p. 148-160. 
Manuscript approved on October 10, 2018

For more information about this publication, contact

Director,

Astrogeology Science Center

U.S. Geological Survey

2255 N. Gemini Dr.

Flagstaff, AZ 86001

For additional information visit https://astrogeology.usgs.gov/

Publishing support provided by the

Menlo Park Publishing Service Center 